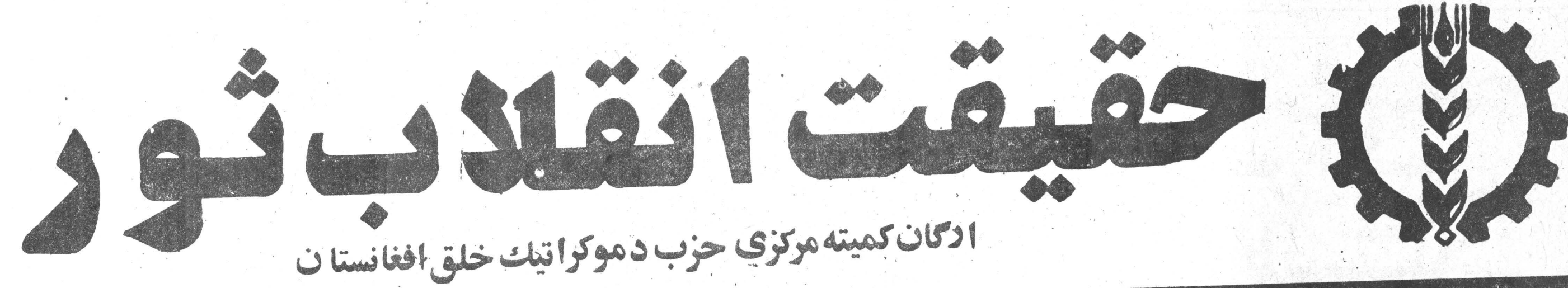

ir

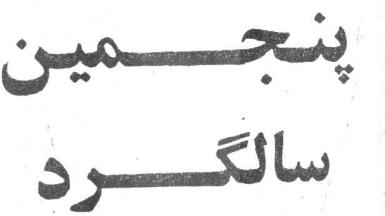

روزنسامسه

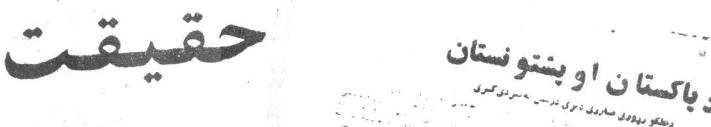

انســـلاب

3

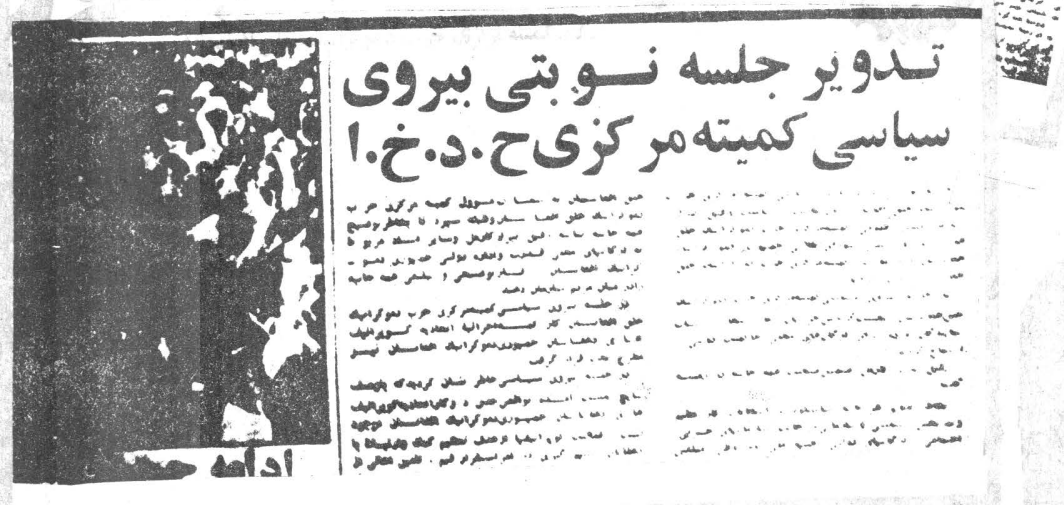

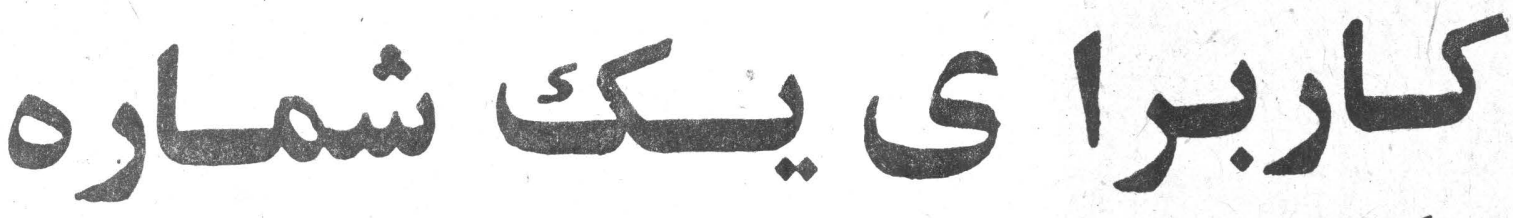

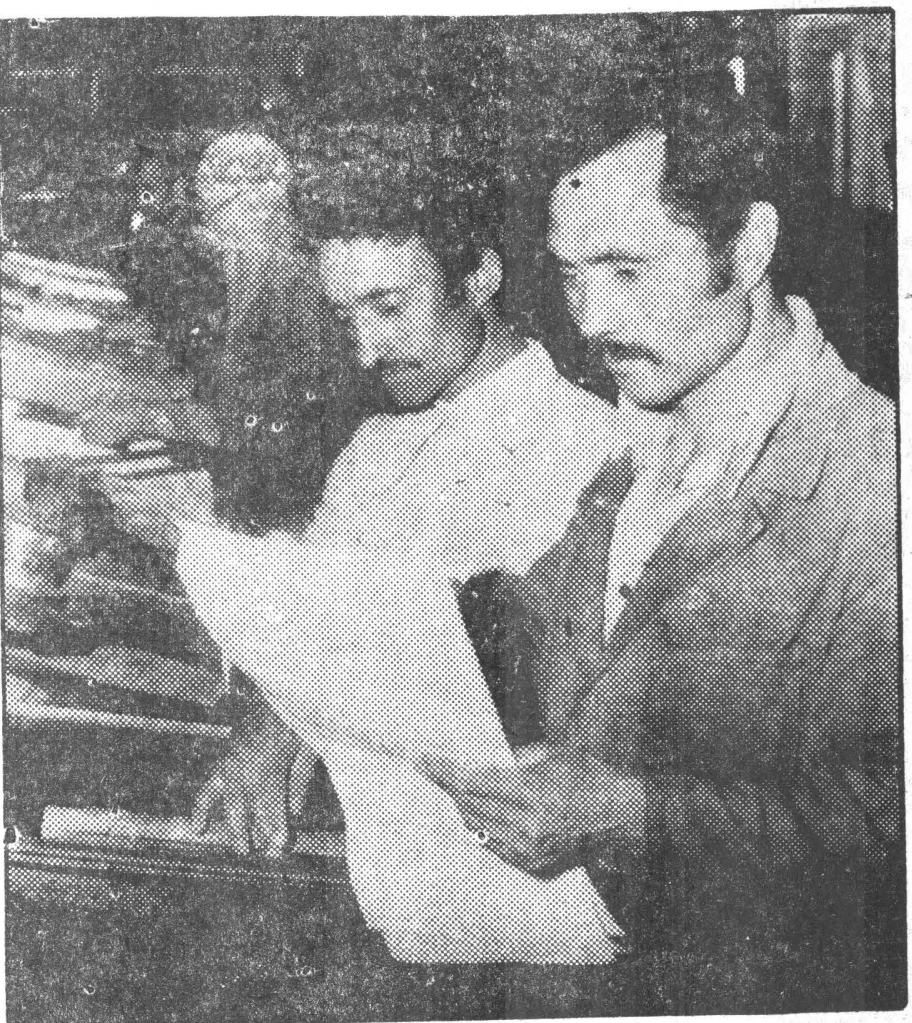

روز معهولا، همينكه يك شمازه

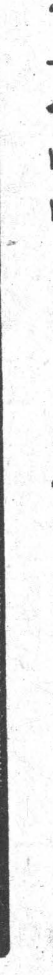

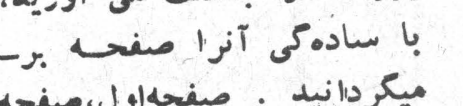

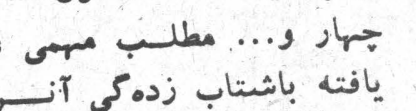

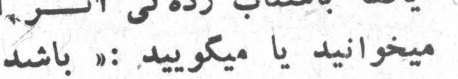

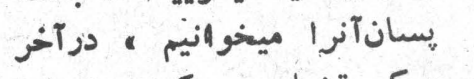

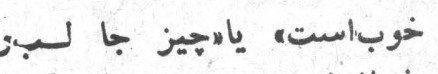

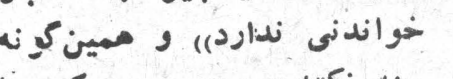

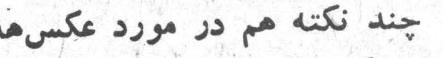

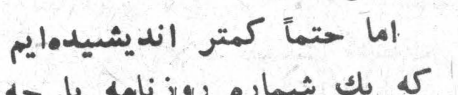

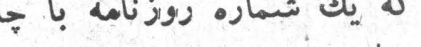

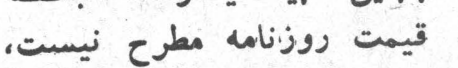
نفردركار نشرآنيذير اميكردني

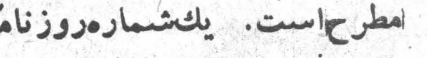

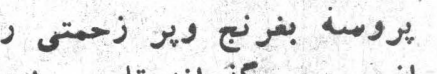

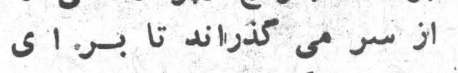

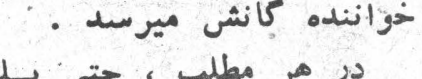

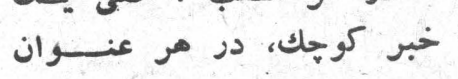

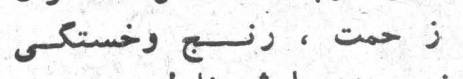

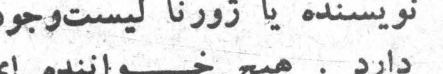

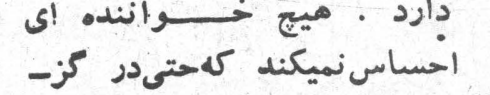

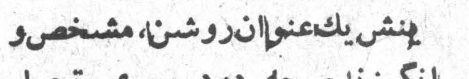

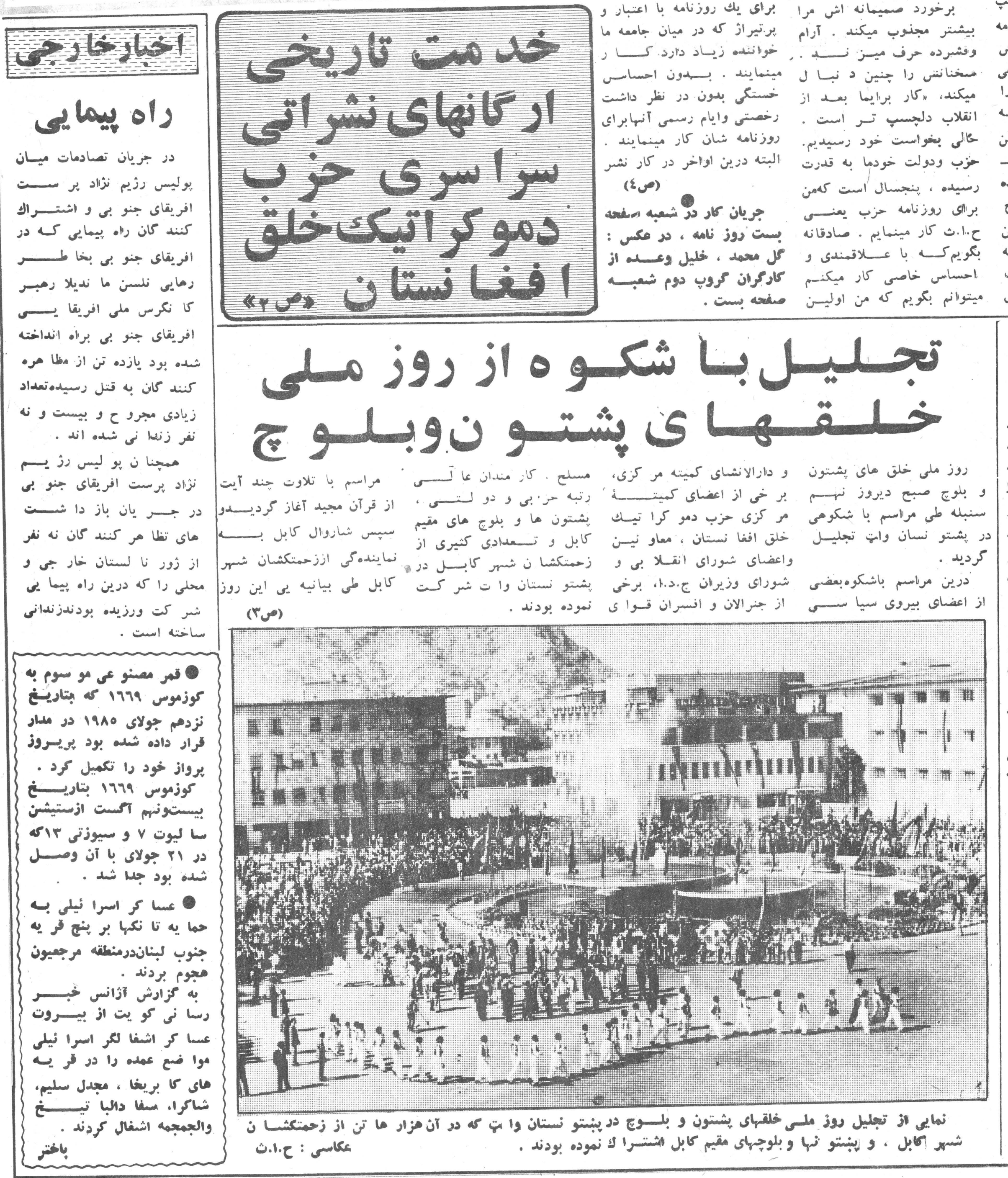

\section{نظر خوانتها}




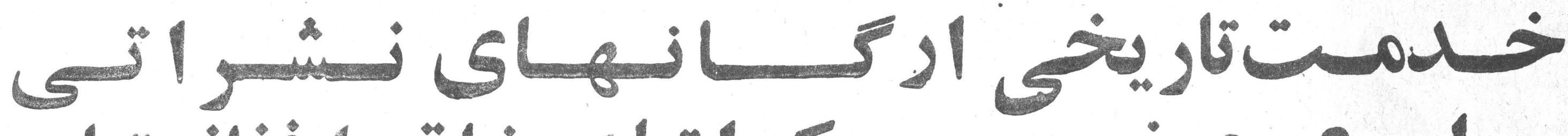

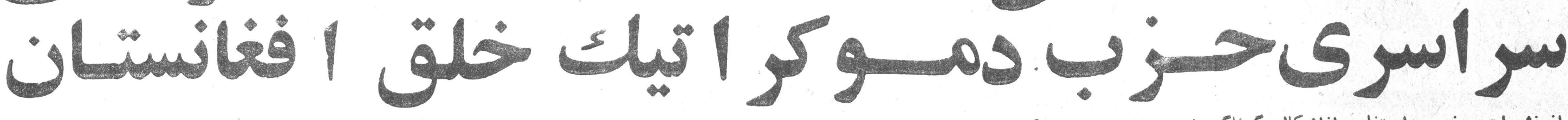

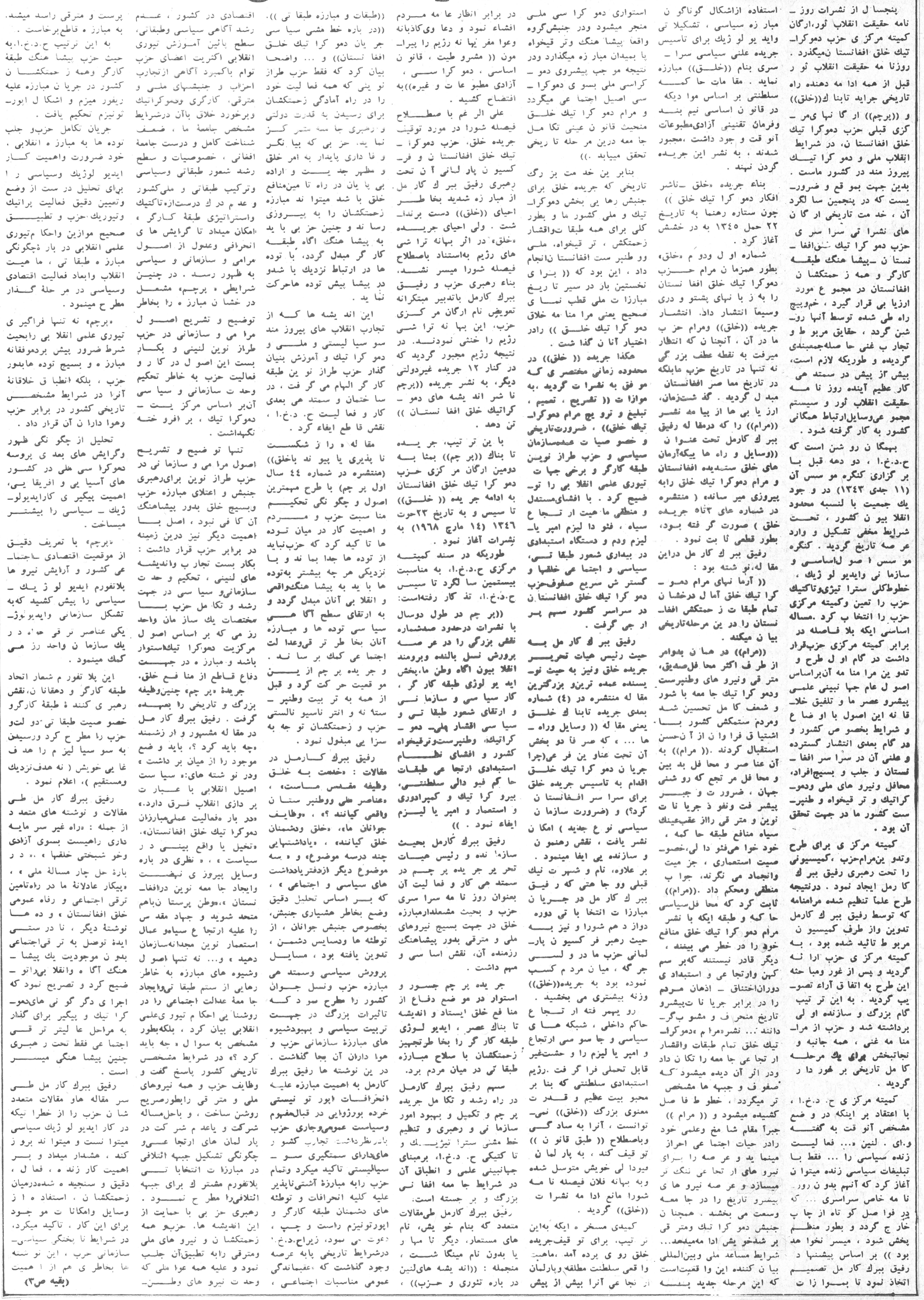




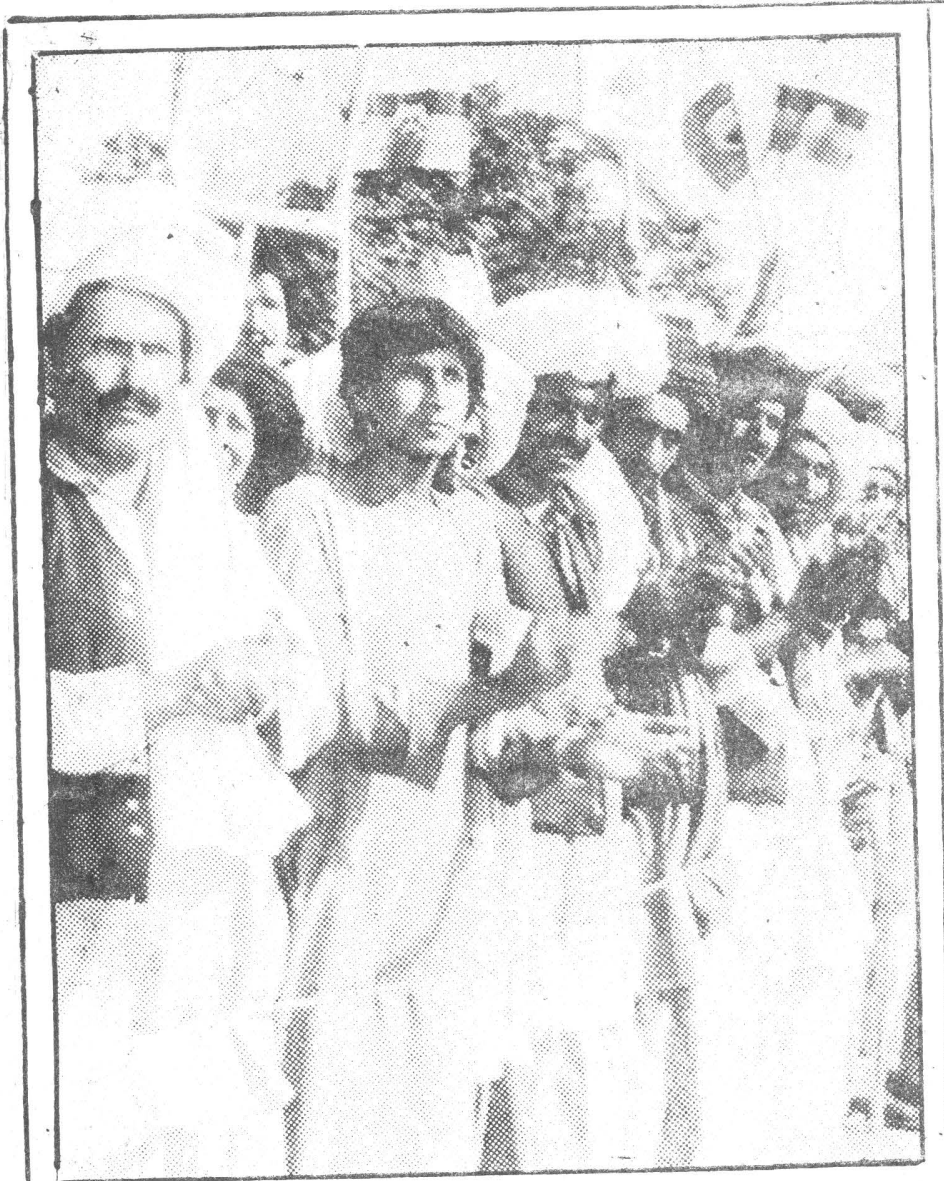

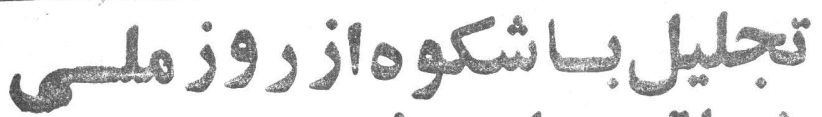

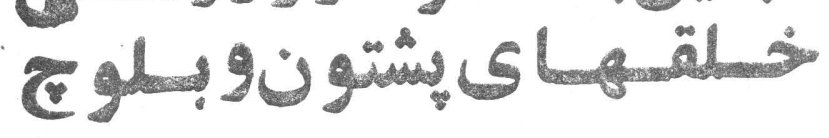

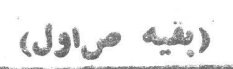

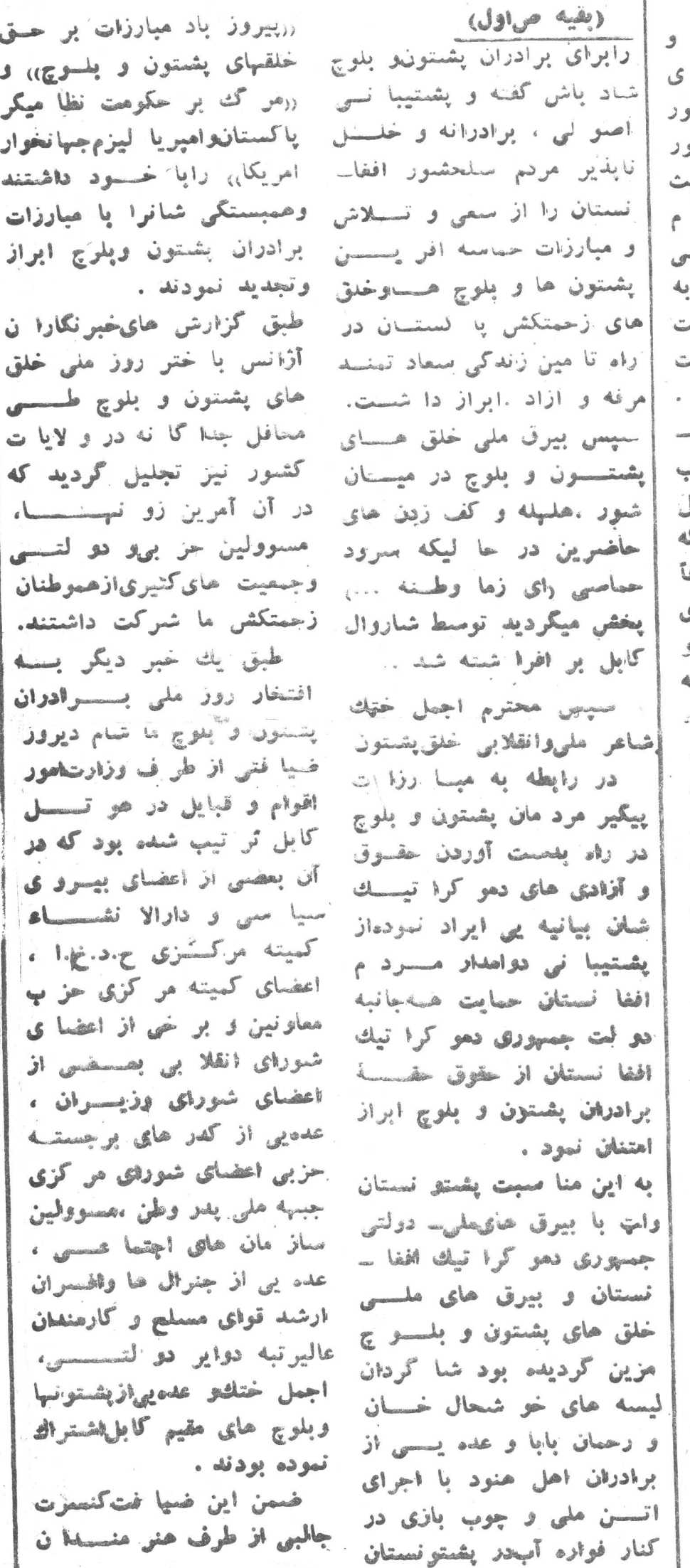

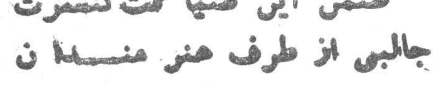

.

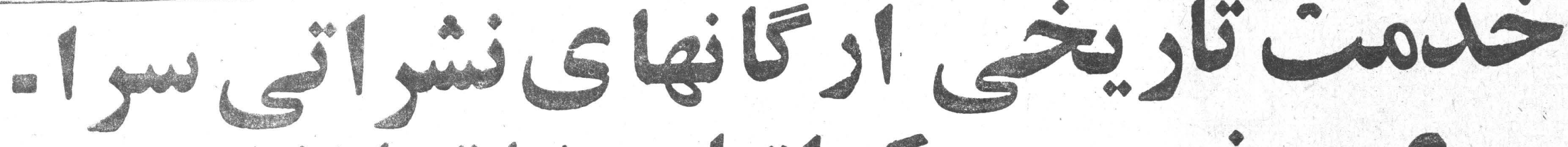

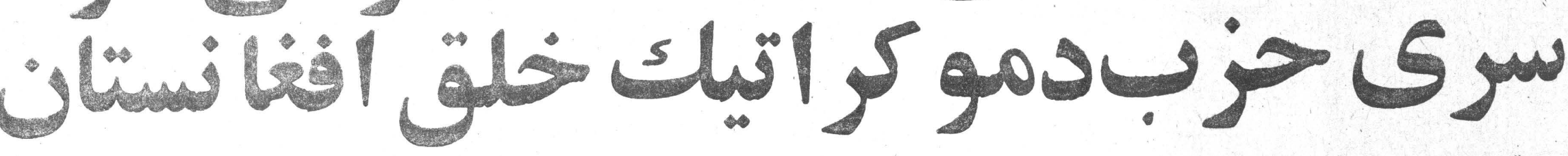

\section{(بقيه م (ه)}

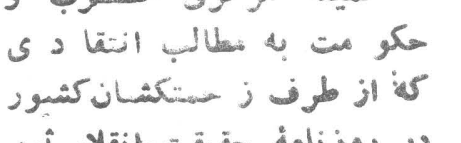

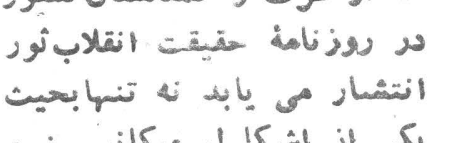

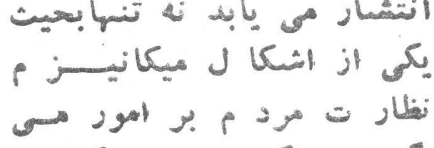

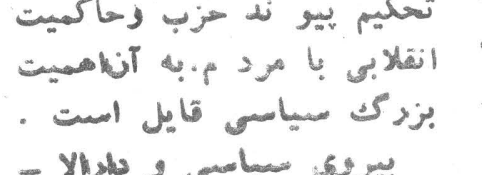

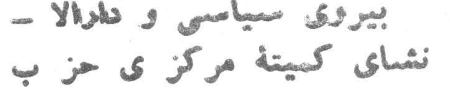

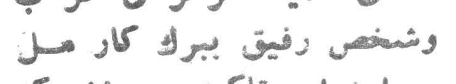

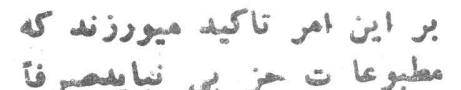

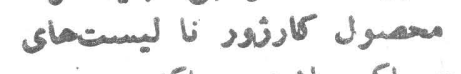

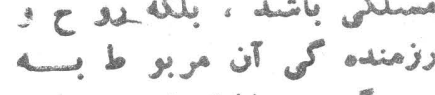

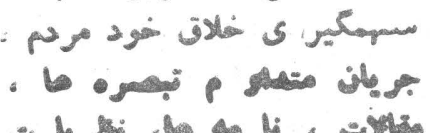
- 6. 6 .

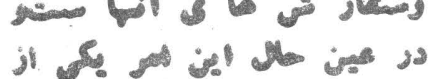
ته

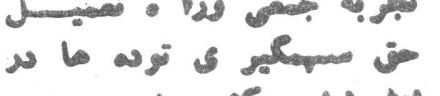
به

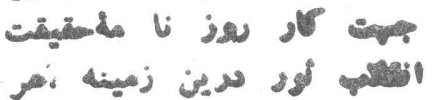
ى

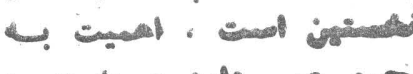

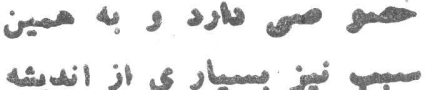

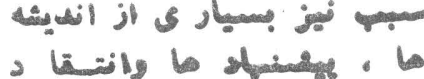

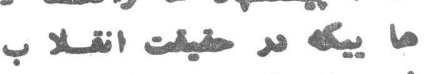

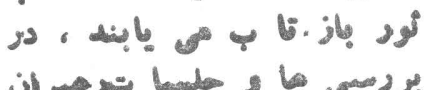

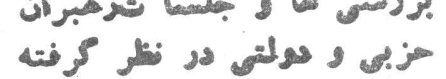

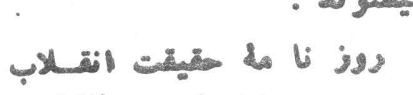

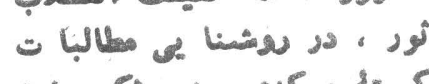

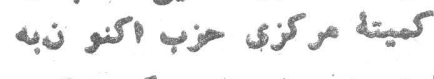

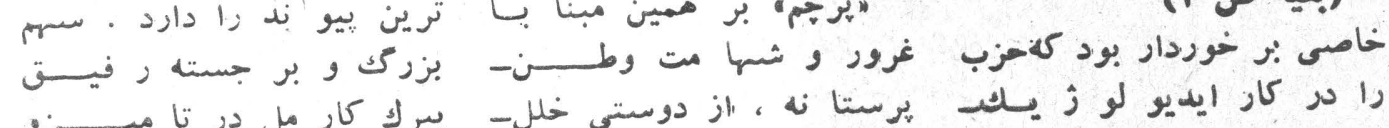

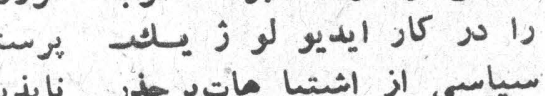

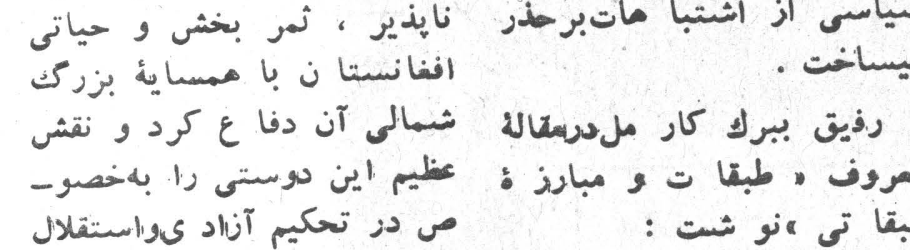

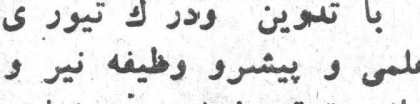

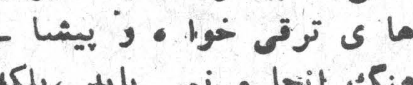
اغا ز ميكردد . به ائن ائ معنم

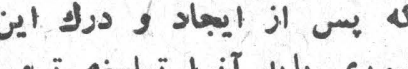

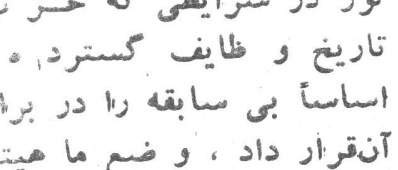

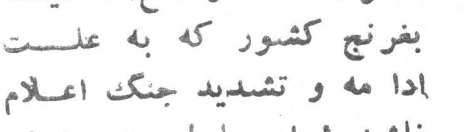

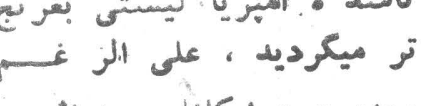

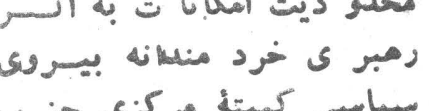

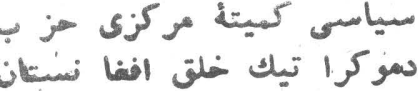

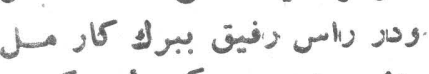

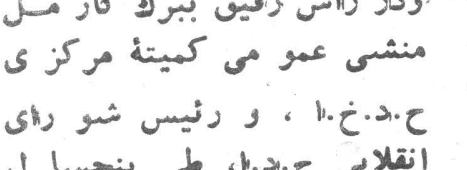

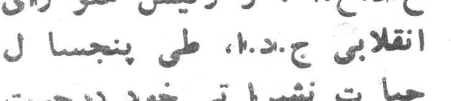

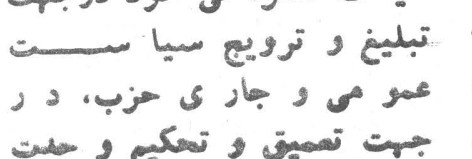

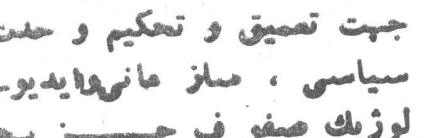

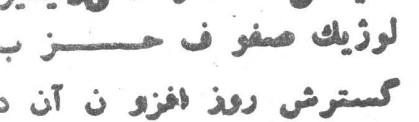

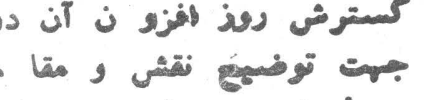

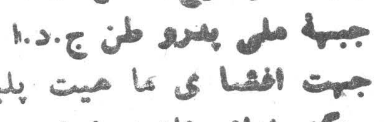

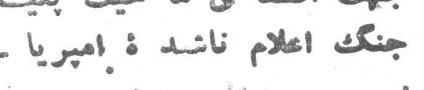

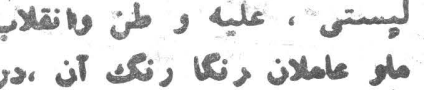

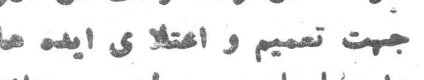

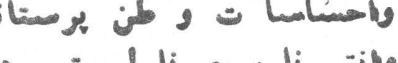

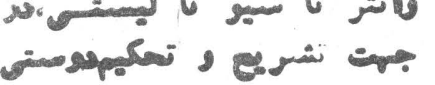

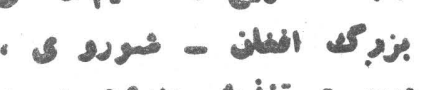

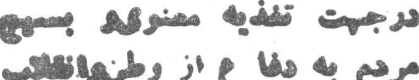

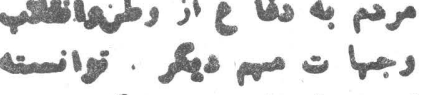

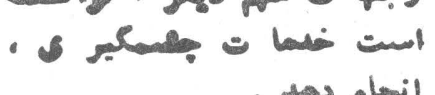

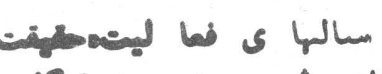

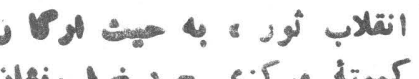

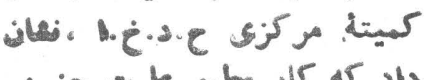

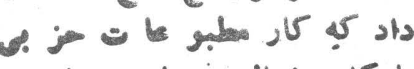

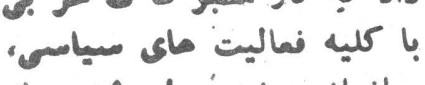

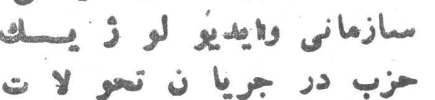

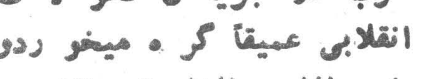

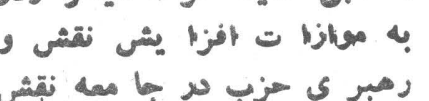

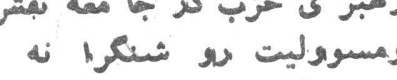

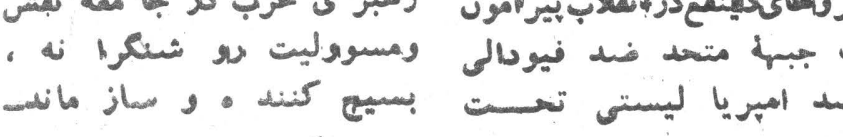

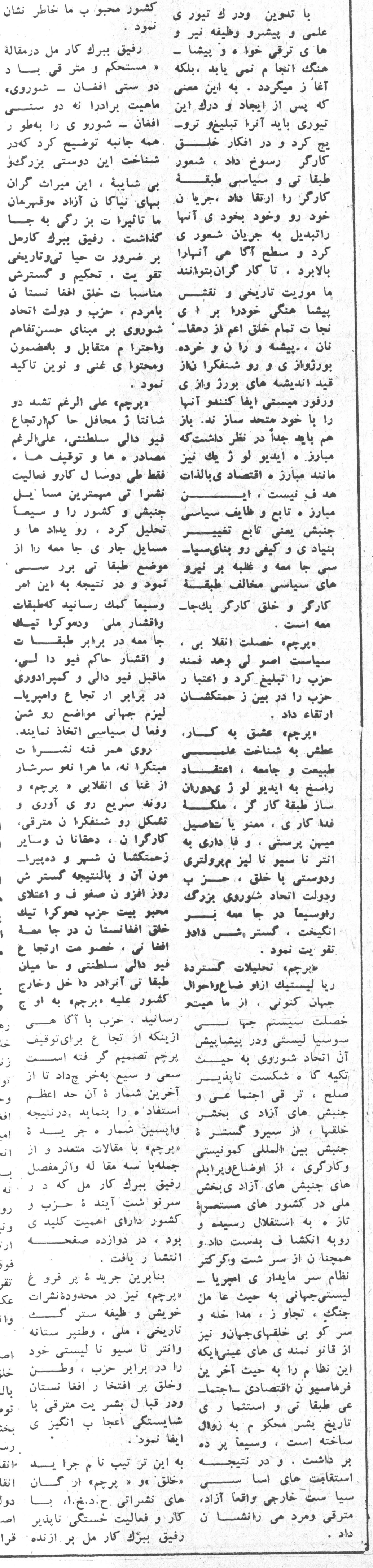




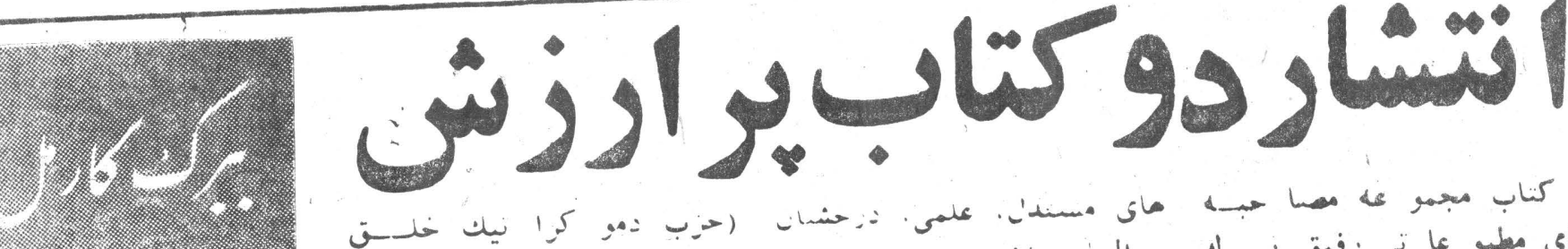

$\cos ^{2} 6$
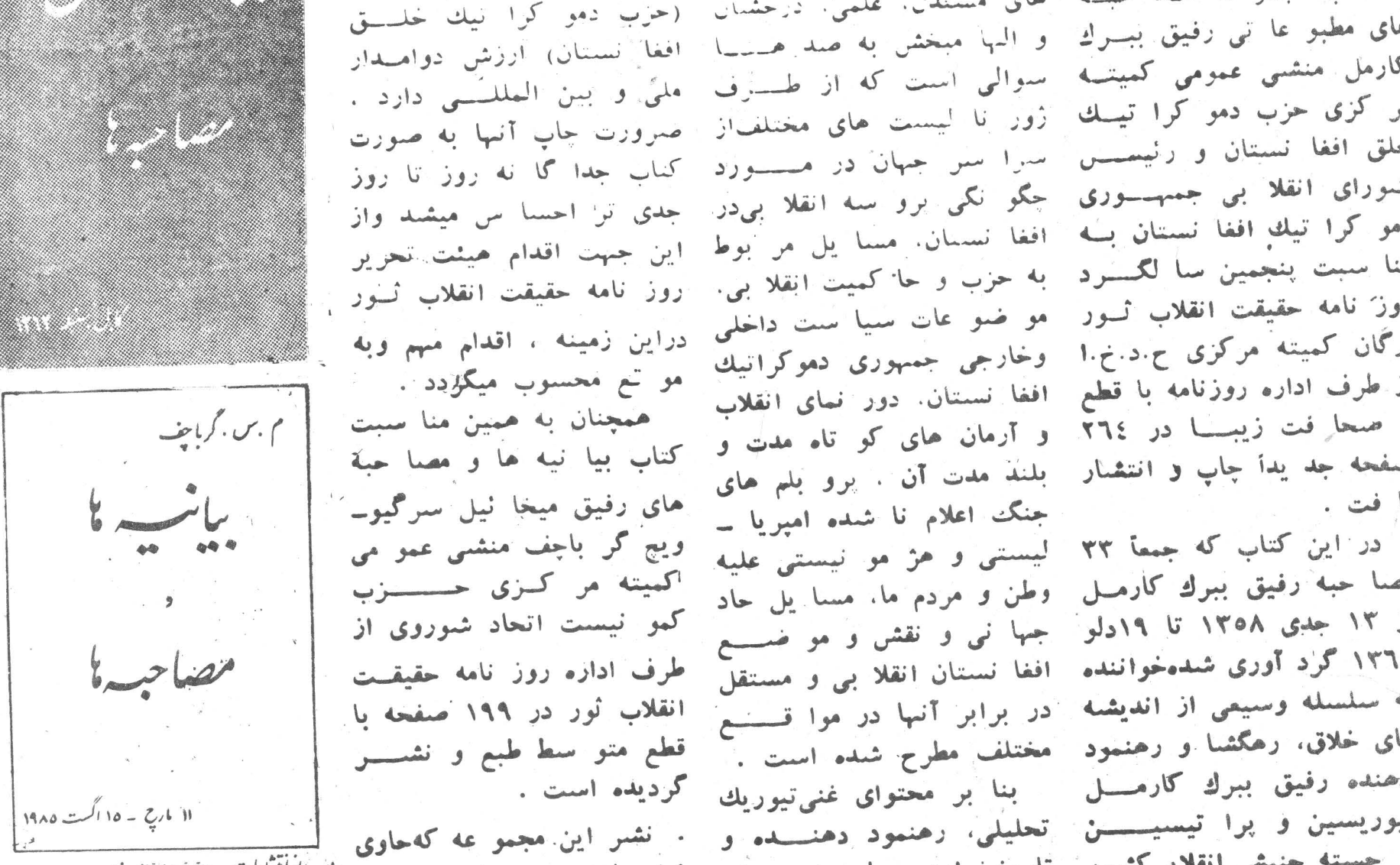

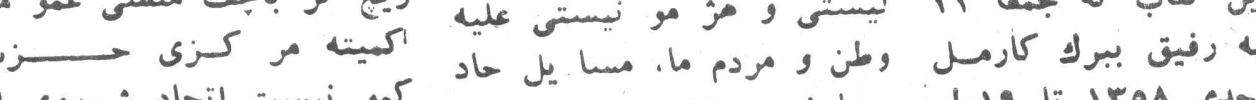

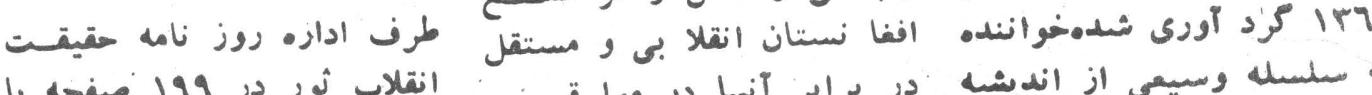

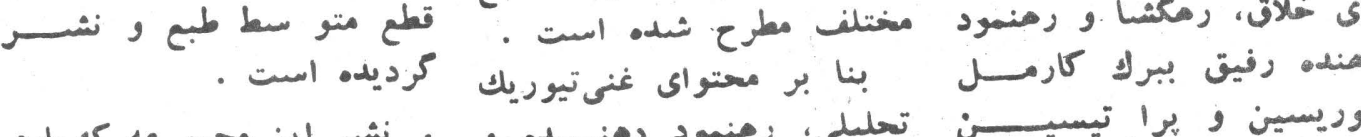

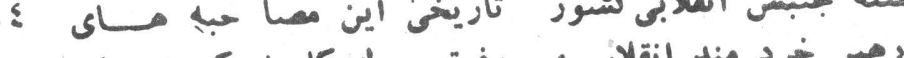

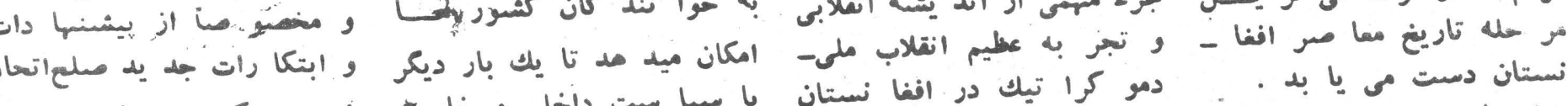

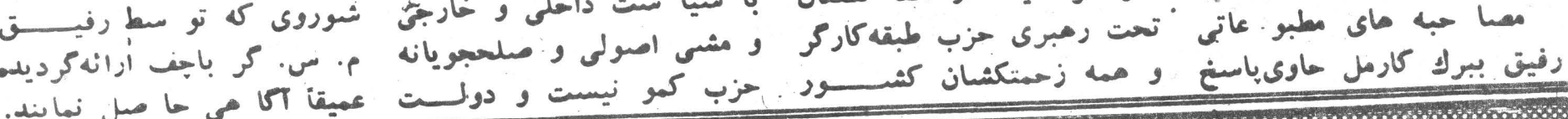
(3)

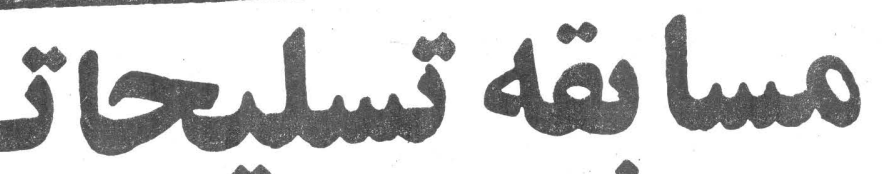 \\ 6 ris ذوروى را مهار كمار}

بـخاطر آزادى

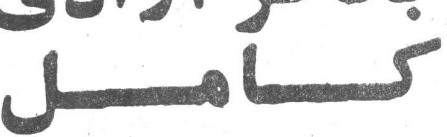

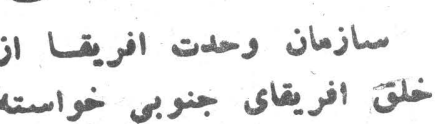

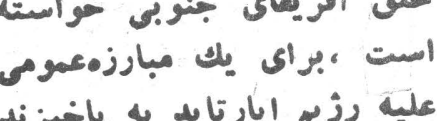

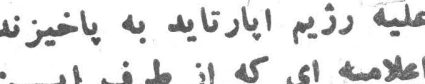

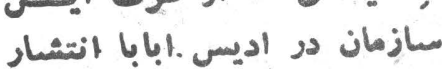

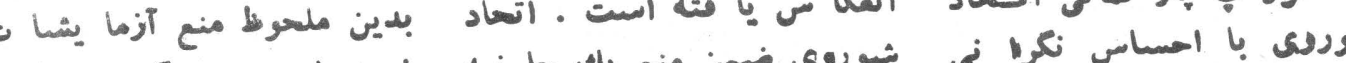

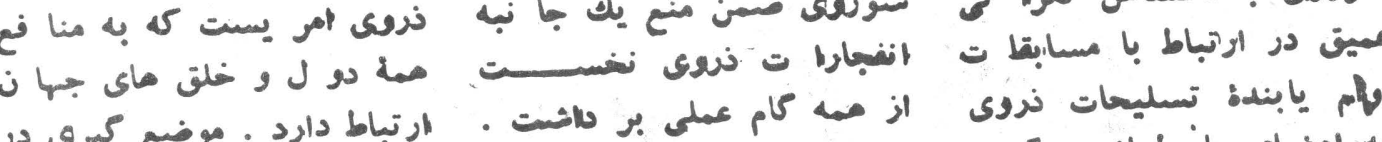

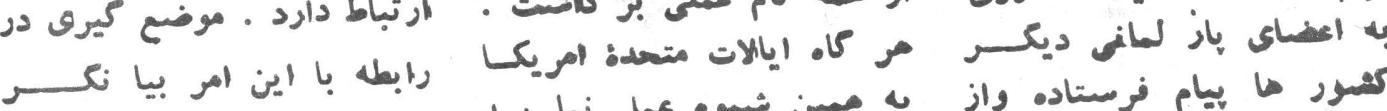

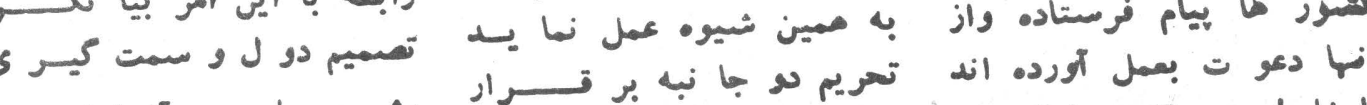

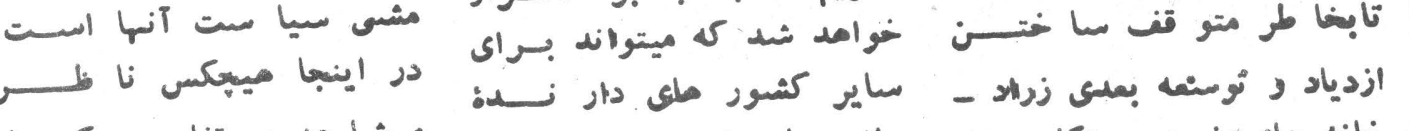

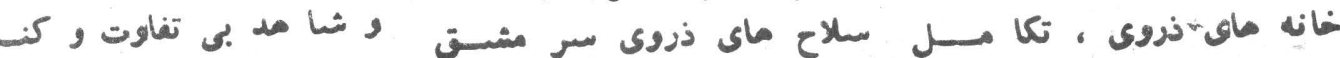

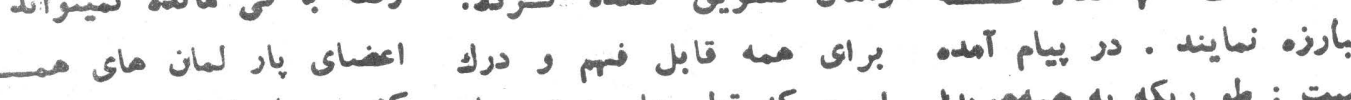

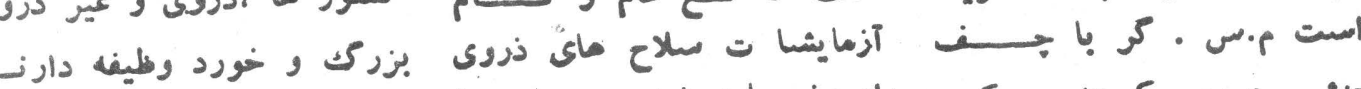

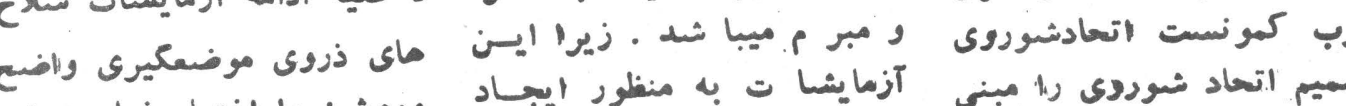

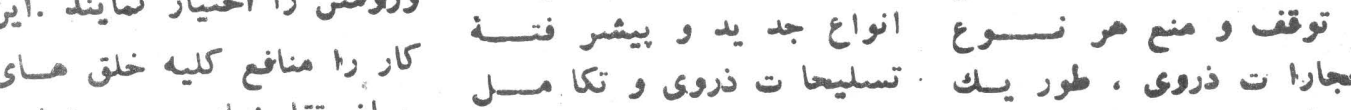

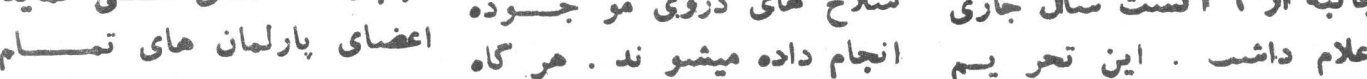

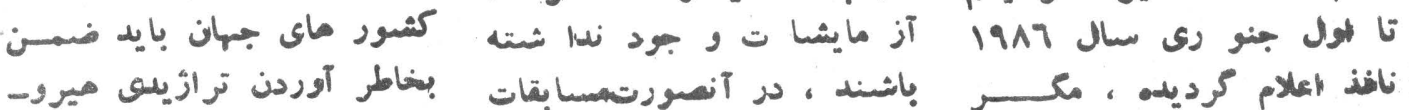

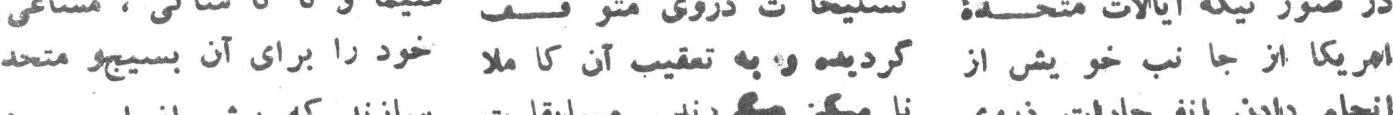

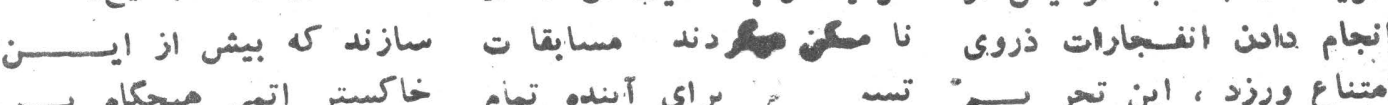

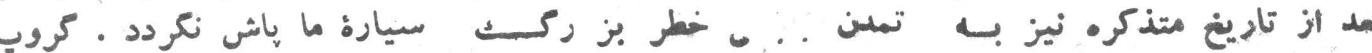

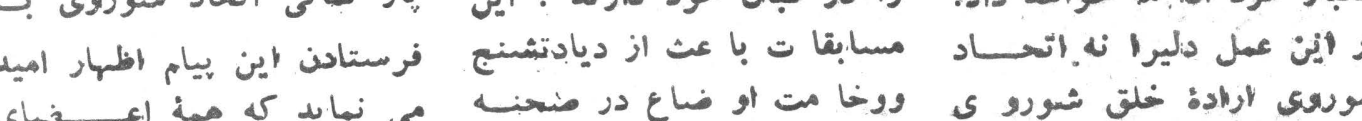

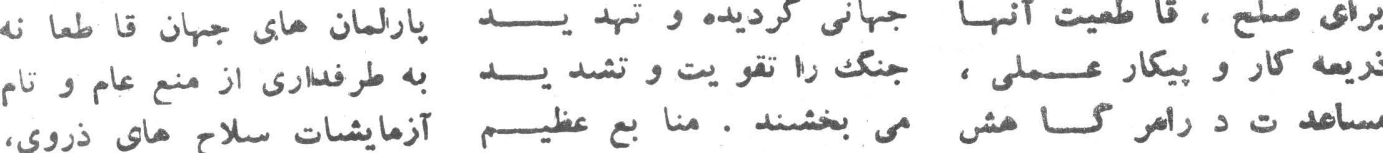

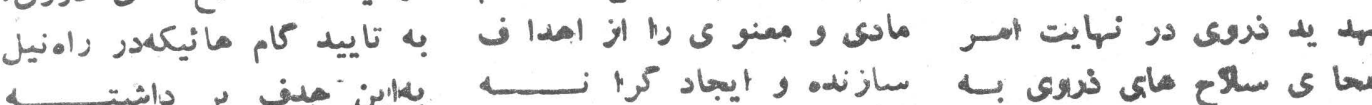

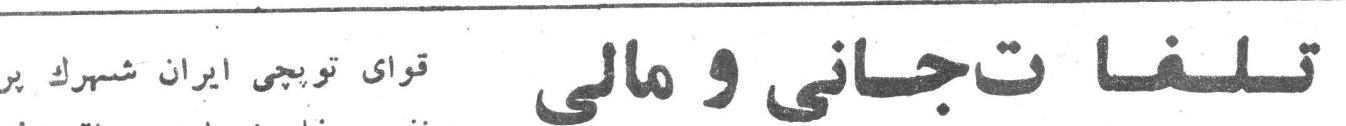

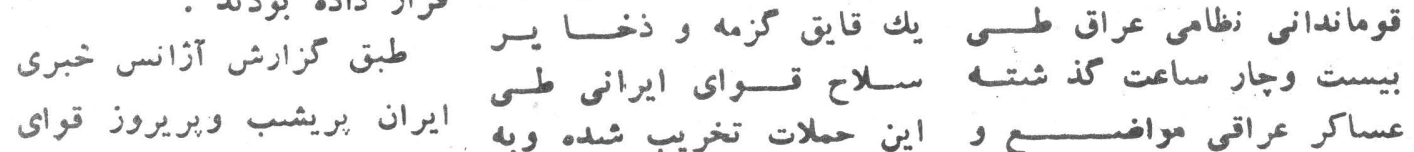

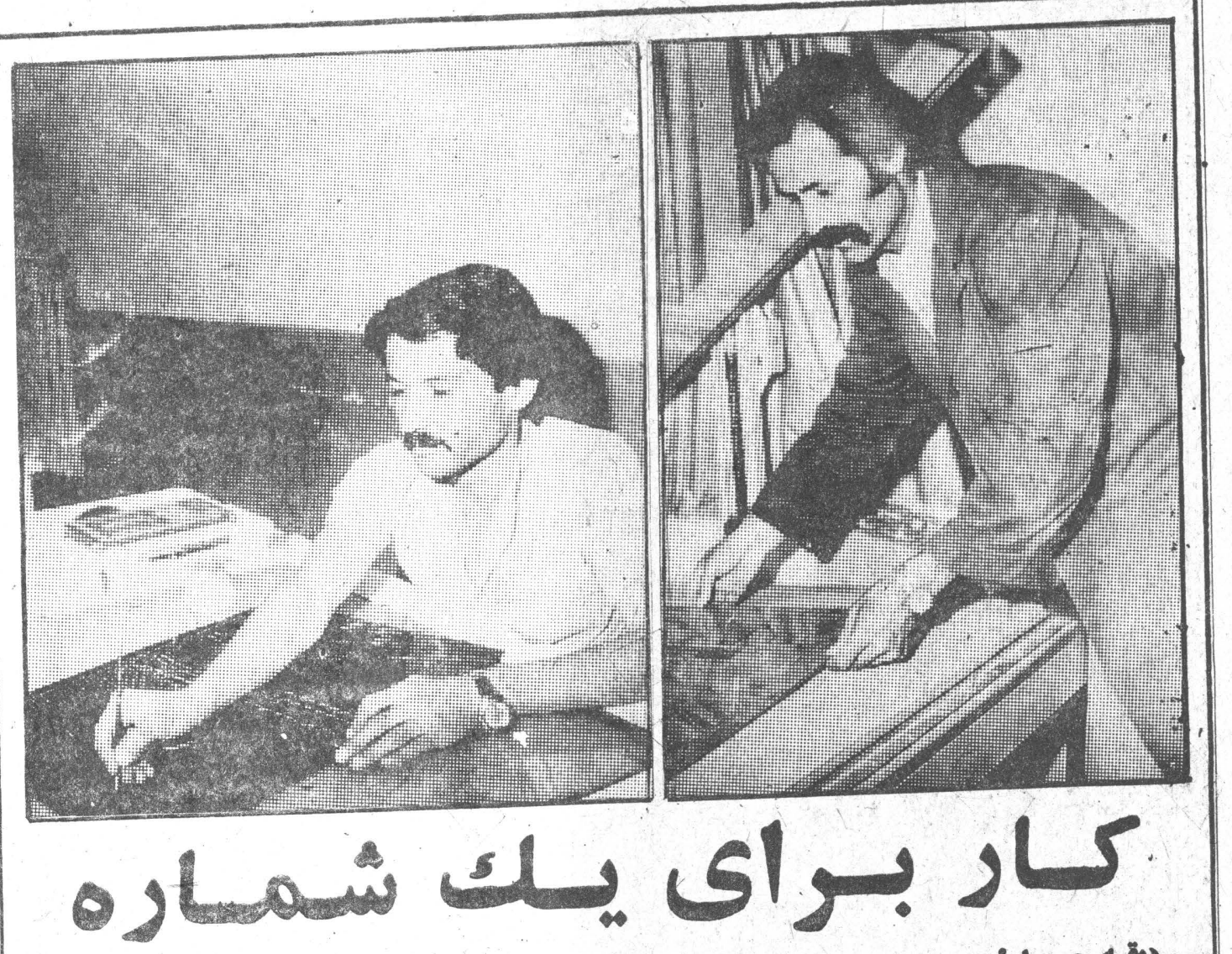

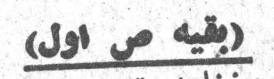

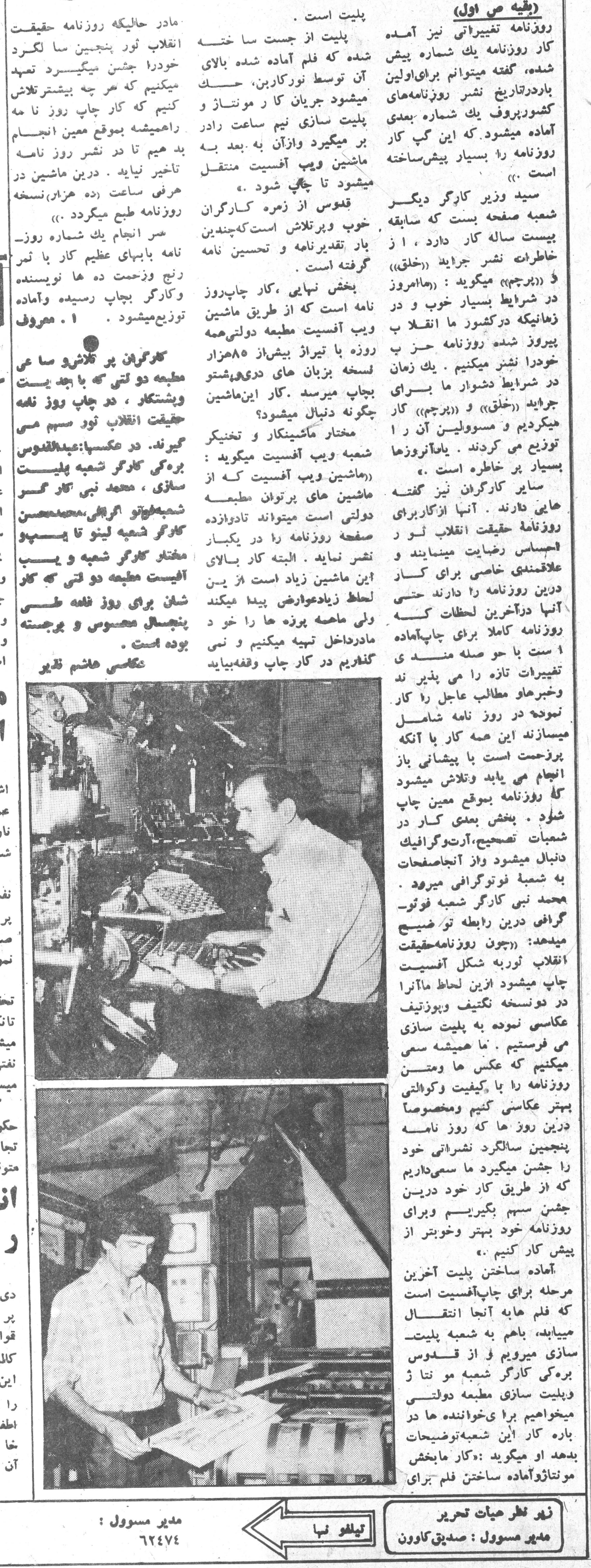

